\title{
Fracture liaison services: past, present and future
}

\section{Editorial relating to: The impact of Fracture Liaison Services on subsequent fractures and mortality: a systematic literature review and meta-analysis}

\author{
K. Ganda ${ }^{1,2}$ (iD) \\ Received: 1 April 2021 / Accepted: 28 April 2021 / Published online: 16 July 2021 \\ (C) Crown 2021
}

A fracture due to minimal trauma (an impact equivalent to a fall from standing height or lesser impact) is the hallmark of osteoporosis [1]. More than half of postmenopausal women and a third of men over the age of 60 years will experience at least one MTF during their remaining lifetime [2]. There were an estimated 9 million fractures related to osteoporosis in 2000 , equating to one fracture every 3 seconds [3]. This figure is set to increase rapidly in the coming decades due to population growth and an ageing population. Therefore, fractures place a heavy burden on individuals, healthcare workers and society through their impact on healthcare system costs.

A minimal trauma fracture (MTF) aka osteoporotic or fragility fracture is associated with significant morbidity and mortality. Individuals who have sustained a MTF are at least two times more likely to sustain further fractures, especially within the first two years after the initial fracture [4, 5]. People with vertebral or hip fractures have a further heightened risk of refracture, i.e. more than fourfold [6-8]. Although men are less likely to sustain initial fractures than women, men are more likely to sustain a refracture and have higher mortality after the initial fracture [5, 9]. Furthermore, excess mortality occurs after all proximal osteoporotic fractures, particularly in the first five years. This risk may persist for up to 10 years after a hip fracture [9].

Pharmacotherapy for osteoporosis is safe and effective in reducing the risk of further vertebral fractures by up to $70 \%$, hip by up to $50 \%$ and non-hip, non-vertebral fractures by 20 $30 \%$ [10-16]. However, despite the wide availability of antiosteoporosis drugs, fewer than $20 \%$ of patients are appropri-

K. Ganda

kirtan.ganda@sydney.edu.au

1 Department of Endocrinology, Concord Hospital, Sydney, Australia

2 Concord Clinical School, University of Sydney, Sydney, Australia ately assessed and treated for the underlying cause of their fragility fracture (i.e. osteoporosis) [17].

To address the care gap in osteoporosis management, centres across the world have developed systematic, coordinated interventions to identify patients who have sustained a minimal trauma fracture, investigate and determine fracture risk, and initiate interventions to reduce fracture risk. A 2013 systematic review [18] divided interventions into four models of care, according to intervention intensity (Table 1). It was demonstrated that more intensive models of care have better outcomes.

Effective secondary fracture prevention programmes (SFPPs; also known fracture liaison services or FLS) cover the three ' $i$ 's' of identification, investigation and initiation of therapy. FLSs were first instituted and reported on in the early 2000s and have since grown globally. The first publications relating to FLS were from Switzerland (Chevalley et al. 2002) [19] and the UK (McLellan et al. 2003) [20]. In the early years, most FLSs reported on process measures such as rates of investigation and treatment; however, as follow-up duration has increased, this further expanded to include refractures and mortality which fed into cost-effectiveness analyses.

Cost-effectiveness of FLS has been demonstrated consistently across the world, from Australia, the USA, the UK, Europe and Asia [21]. FLS are associated with gains in quality-adjusted life years (QALY) for costs below the willingness to pay thresholds in most jurisdictions. The cost per QALY for FLSs varies by country. That is, in Australia, it is \$17,291-\$31,749 AUD per QALY, in Canada \$8368 to 76,428 CAD per QALY and in Sweden 14,029 Euro per QALY. One must keep in mind that it is difficult to compare across studies due to variations in baseline characteristics (e.g. fracture sites), availability of pharmacotherapy, staff costs, costs of osteoporosis pharmacotherapy and adherence. Moreover, assumptions in the economic modelling can vary between countries and studies. 
Table 1 Secondary fracture prevention models of care

\begin{tabular}{|c|c|}
\hline $\begin{array}{l}\text { Intervention } \\
\text { model of care }\end{array}$ & Description \\
\hline A & $\begin{array}{l}\text { Identification, assessment } \\
\text { (risk factors, blood, BMD), } \\
\text { treatment initiation }\end{array}$ \\
\hline B & $\begin{array}{l}\text { Identification, assessment, } \\
\text { treatment recommendation only }\end{array}$ \\
\hline $\mathrm{C}$ & $\begin{array}{l}\text { Education of patient and primary } \\
\text { care physician }\end{array}$ \\
\hline $\mathrm{D}$ & Education of patient only \\
\hline
\end{tabular}

\section{Heterogeneity in reporting of outcomes}

According to previous systematic reviews [18, 21, 22], FLSs have demonstrated improved osteoporosis treatment initiation and reductions in refracture rates compared to standard care. However, meta-analyses and systematic reviews of outcome measures from FLS have been difficult to interpret due to heterogeneity in reporting of outcome measures and varying baseline characteristics in the participants. Studies vary in terms of gender proportions, fracture sites included and criteria for pharmacotherapy. Moreover, in the case of further fractures, the study design can vary, as the control group may be historical or concurrent. There has been inconsistent reporting of a number of outcome measures including identification rates, captures rates and treatment initiation rates. Identification rates are likely to be under-estimated in most FLSs as they are under-resourced, and/or lack technology for the systematic identification of patients with fragility fractures. Thus, most FLSs fail to capture patients with vertebral fractures, as these are often asymptomatic or do not present to hospital. Capture rates (i.e. the proportion of those identified that are seen in the FLS) are not always reported by FLSs. Treatment rates may vary between health networks and countries due to different diagnostic and treatment thresholds. For example, in a study by McLellan et al. [19], pharmacotherapy was initiated if the T-score was less than -2.0 SD. This threshold, however, differs from that of other centres [23]. The choice of pharmacotherapy would also vary depending on access in different parts of the world.

With the development of more FLSs worldwide, there has been a drive towards the development of FLS standards which may help to benchmark their performance over time. A positive step towards helping to standardise processes and outcomes for FLSs globally has been the IOF Capture the Fracture programme and Best Practice Framework. According to the latest data from the Capture the Fracture website, there was 583 FLSs from 48 countries who have submitted their data. Of note, there is poor representation from countries in Africa, the Indian subcontinent and China, which may be a reflection of different health priorities in these regions.
A further development has been the institution of FLS registries which is again aimed at standardisation of processes and outcome measures to enable benchmarking over the long term. One of the hurdles in setting up a registry is ensuring individual FLS and the registries have sufficient funding and resources for ongoing data collection and feedback. Having robust evidence that FLSs reduce further fractures and mortality is therefore critical to make the case for the funding of these activities.

Therefore, the article by $\mathrm{Li}$ et al. in this edition of the journal comes at an opportune time in the landscape of secondary fracture prevention efforts globally. Li and colleagues have presented a succinct yet thorough systematic review and meta-analysis of fracture liaison services (FLSs) or secondary fracture prevention programmes over the last 10 years, focussing upon the outcome measure of further fractures and mortality. As opposed to process measures such as rates of investigation or treatment for osteoporosis, further fractures and mortality are more clinically relevant and can be utilised to determine cost-effectiveness from a healthcare funding perspective.

This paper has demonstrated a $30 \%$ relative reduction in the risk of further fractures with FLS care vs. non-FLS care after a median follow-up of 2 years with the most benefit being demonstrated in studies with 2 or more years of follow-up (43\% relative risk reduction). There was no significant effect in terms of mortality reduction except for the preand post-FLS sub-analysis; however, interpretation is limited by the small number and short duration of studies. Interestingly, the magnitude of reduction in refractures is in keeping with the expected relative risk reduction in non-hip, non-vertebral fractures with osteoporosis pharmacotherapy as demonstrated in RCTs. However, FLSs manage other aspects of SFP including optimisation of calcium and vitamin D intake, as well as falls risk reduction, and therefore, one would expect to have further fracture risk reduction in addition to osteoporosis pharmacotherapy.

One of the strengths of this article is the utilisation of a scoring system or checklist to assess the quality of the articles tailored to evaluating FLS studies. For example, ensuring that at least $50 \%$ of those identified are seen in the FLS was an important aspect of the analysis which helped to assess the risk of bias. The other aspect of the checklist which is worthwhile noting is that only 3 of 16 studies had a sample size based on a power calculation. This method of assessing the quality of each study however has not been validated but are useful pointers to guide future FLS researchers to ensure these aspects are covered when presenting their results for publication.

One important consideration which was discussed in the paper was the reporting of fractures taking into account the competing risk of mortality. As the risk of mortality is increased after a fracture, reporting further fractures whilst censoring those who die may result in an over-estimation of 
fracture risk. In this study, amongst the 16 studies reporting on further fracture outcomes, only four adjusted for the competing risk of mortality. The present study did not take this into account in the meta-analysis, as further fractures were recorded as crude events in most studies (apart from 4 of 16 studies). Reassuringly, a sub-analysis of three of these studies before and after taking into account the competing risk of mortality did not change the results. Therefore, future studies from FLSs should ensure the competing risk of mortality is taken into account when reporting on further fractures.

Long-term RCTs of FLS vs non-FLS care are difficult to justify because not managing a patient with a MTF for future fracture risk would constitute negligent patient care in view of the strong evidence for fracture risk reduction with antiosteoporosis pharmacotherapy as well as falls risk reduction strategies. Thus, as demonstrated in this systematic review, study sites have had to resort to demonstrating fracture risk reduction through pre- vs post-FLS analyses as well as comparing hospitals or facilities with vs. without a FLS. Although this is not ideal, it is still worthwhile, as this is probably the best level of evidence we are likely to achieve to demonstrate fracture risk reduction with FLSs.

\section{Conclusion}

Fracture liaison services and associated literature have developed and progressed at a steady pace over the last two decades. With the ongoing publication of long-term data, this systematic review and meta-analysis of FLSs is a significant contribution to the FLS literature as it provides further evidence of the significant and clinically relevant benefits of instituting FLSs worldwide. This will certainly help support FLS funding through demonstration fracture risk reduction and thus cost-effectiveness. Despite this, further work should focus on improving the identification of all patients with MTFs through automated systems, standardised reporting of FLS characteristics and outcome measures.

\section{Declarations}

Conflicts of interest None.

\section{References}

1. World Health Organization (1994) Assessment of fracture risk and its application to screening for postmenopausal osteoporosis: report of a WHO study group [meeting held in Rome from 22 to 25 June 1992]. WHO, Geneva

2. Nguyen ND, Ahlborg HG, Center JR, Eisman JA, Nguyen TV (2007) Residual lifetime risk of fractures in women and men. J Bone Miner Res 22:781-788
3. Johnell O, Kanis JA (2006) An estimate of the worldwide prevalence and disability associated with osteoporotic fractures. Osteoporos Int 17(12):1726-1733

4. Johnell O, Kanis JA, Oden A et al (2004) Fracture risk following an osteoporotic fracture. Osteoporos Int 15:175-179

5. Center JR, Bliuc D, Nguyen TV, Eisman JA (2007) Risk of subsequent fracture after low-trauma fracture in men and women. JAMA 297:387-394

6. Pongchaiyakul C, Nguyen ND, Jones G, Center JR, Eisman JA, Nguyen TV (2005) Asymptomatic vertebral deformity as a major risk factor for subsequent fractures and mortality: a long-term prospective study. J Bone Miner Res 20:1349-1355

7. Johansson H, Oden A, McCloskey EV, Kanis JA (2014) Mild morphometric vertebral fractures predict vertebral fractures but not nonvertebral fractures. Osteoporos Int 25:235-241

8. Klotzbuecher CM, Ross PD, Landsman PB, Abbott TA, Berger M (2000) Patients with prior fractures have an increased risk of future fractures: a summary of the literature and statistical synthesis. J Bone Miner Res 15:721-739

9. Bliuc D, Nguyen ND, Nguyen TV, Eisman JA, Center JR (2013) Compound risk of high mortality following osteoporotic fracture and refracture in elderly women and men. J Bone Miner Res 28: 2317-2324

10. Harris ST, Watts NB, Genant HK, McKeever CD, Hangartner T, Keller M, Chesnut CH 3rd, Brown J, Eriksen EF, Hoseyni MS, Axelrod DW, Miller PD (1999) Effects of risedronate treatment on vertebral and nonvertebral fractures in women with postmenopausal osteoporosis: a randomized controlled trial. Vertebral Efficacy With Risedronate Therapy (VERT) Study Group. Jama. 282(14):1344-1352

11. Black DM, Thompson DE, Bauer DC, Ensrud K, Musliner T, Hochberg MC, Nevitt MC, Suryawanshi S, Cummings SR (2000) Fracture risk reduction with alendronate in women with osteoporosis: the Fracture Intervention Trial. FIT Research Group. J Clin Endocrinol Metab. 85(11):4118-4124

12. Cummings SR, San Martin J, McClung MR, Siris ES, Eastell R, Reid IR, Delmas P, Zoog HB, Austin M, Wang A, Kutilek S, Adami S, Zanchetta J, Libanati C, Siddhanti S, Christiansen C (2009) Denosumab for prevention of fractures in postmenopausal women with osteoporosis. New Engl J Med. 361(8):756-765

13. Cummings SR, Black DM, Thompson DE, Applegate WB, BarrettConnor E, Musliner TA, Palermo L, Prineas R, Rubin SM, Scott JC, Vogt T, Wallace R, Yates AJ, LaCroix AZ (1998) Effect of alendronate on risk of fracture in women with low bone density but without vertebral fractures: results from the Fracture Intervention Trial. Jama. 280(24):2077-2082

14. Lyles KW, Colon-Emeric CS, Magaziner JS, Adachi JD, Pieper CF, Mautalen C, Hyldstrup L, Recknor C, Nordsletten L, Moore KA, Lavecchia C, Zhang J, Mesenbrink P, Hodgson PK, Abrams K, Orloff JJ, Horowitz Z, Eriksen EF, Boonen S, Trial HRF (2007) Zoledronic acid and clinical fractures and mortality after hip fracture. N Engl J Med. 357(18):1799-1809

15. Black DM, Delmas PD, Eastell R, Reid IR, Boonen S, Cauley JA, Cosman F, Lakatos P, Leung PC, Man Z, Mautalen C, Mesenbrink $\mathrm{P}, \mathrm{Hu} \mathrm{H}$, Caminis J, Tong K, Rosario-Jansen T, Krasnow J, Hue TF, Sellmeyer D, Eriksen EF, Cummings SR (2007) Once-yearly zoledronic acid for treatment of postmenopausal osteoporosis. $\mathrm{N}$ Engl J Med 356(18):1809-1822

16. Neer RM, Arnaud CD, Zanchetta JR, Prince R, Gaich GA, Reginster JY, Hodsman AB, Eriksen EF, Ish-Shalom S, Genant HK, Wang O, Mitlak BH (2001) Effect of parathyroid hormone (1-34) on fractures and bone mineral density in postmenopausal women with osteoporosis. N Engl J Med. 344(19):1434-1441

17. Leslie WD, Giangregorio LM, Yogendran M, Azimaee M, Morin S, Metge C, Caetano P, Lix LM (2012) A population-based analysis 
of the post-fracture care gap 1996-2008: the situation is not improving. Osteoporos Int 23:1623-1629

18. Ganda K, Puech M, Chen JS, Speerin R, Bleasel J, Center JR, Eisman JA, March L, Seibel MJ (2013) Models of care for the secondary prevention of osteoporotic fractures: a systematic review and meta-analysis. Osteoporos Int 24(2):393-406

19. McLellan AR, Gallacher SJ, Fraser M, McQuillian C (2003) The fracture liaison service: success of a program for the evaluation and management of patients with osteoporotic fracture. Osteoporos Int 14(12):1028-1034

20. Chevalley T, Hoffmeyer P, Bonjour JP, Rizzoli R (2002) An osteoporosis clinical pathway for the medical management of patients with low-trauma fracture. Osteoporos Int 13:450-455

21. Wu CH, Te Tu S, Chang YF et al (2018) Fracture liaison services improve outcomes of patients with osteoporosis-related fractures: a systematic literature review and meta-analysis. Bone. 111(138):92100

22. Sale JEM, Beaton D, Posen J, Elliot-Gibson V, Bogoch E (2011) Systematic review on interventions to improve osteoporosis investigation and treatment in fragility fracture patients. Osteoporos Int 22:2067-2082

23. Majumdar SR, Beaupre LA, Harley CH, Hanley DA, Lier DA, Juby AG, Maksymowych WP, Cinats JG, Bell NR, Morrish DW (2007) Use of a case manager to improve osteoporosis treatment after hip fracture. Arch Intern Med 167(19):2110-2115

Publisher's note Springer Nature remains neutral with regard to jurisdictional claims in published maps and institutional affiliations. 